\title{
Evaluation of the Influence of Salt Treatment on the Structure of Pyrolyzed Periwinkle Shell
}

\section{*11OWABOR, C N; IYAOMOLERE, A I}

Department of Chemical Engineering, University of Benin, Edo State, Nigeria

\begin{abstract}
This paper investigates the effect of use zinc chloride in varying impregnation ratios ranging between 0.1 and 1.5 to chemically activate carbonized periwinkle shells. Studies to characterize the activated carbon were conducted at ambient conditions. The experimental results revealed that the impregnation ratio at 1.0 gave the optimum values for parameters such as iodine number and porosity; and minimum values for parameters like $\mathrm{pH}$ and moisture content which represent properties for characterizing maximum adsorption. This study successfully demonstrates the potential of $\mathrm{ZnCl}_{2}$ can be used as an activating agent for producing high quality activated carbon which overall has the capacity to impact positively on the quality of the environment. @ JASEM
\end{abstract}

DOI: http:/ / dx.doi.org/10.4314/jasem.v17i2.15

Activated carbon is a black solid substance resembling granular or powdered charcoal. It is a processed carbon material with a highly developed porous structure and a large internal specific surface area (Abdullah et al., 2001, Lysenko, 2007). They are widely used as adsorbents and represent extremely versatile adsorbents of industrial significance. They are employed in many applications which concern principally the removal of undesirable species from liquids or gases (Sharma and Janveja, 2008, Boudrahem et al, 2011).

Typically, the preparation of activated carbon can be divided into two processes. First, the physical method consists of the pyrolysis of the precursor material and gasification of the resulting char in steam or carbon dioxide. The formation of the porous structure is achieved by elimination of a large amount of internal carbon mass. High porosity carbons can be obtained only at a high degree of char burn off. For the chemical method, pyrolysis char would be impregnated with some chemical reagents, such as $\mathrm{ZnCl}_{2}, \mathrm{H}_{3} \mathrm{PO}_{4}, \mathrm{NaOH}$, and $\mathrm{KOH}$. Because of the dehydrogenation process, the chemical reagents promote the formation of cross-links, leading to the development of a rigid matrix, less prone to volatile loss and volume contraction upon usage. Major advantages of the chemical activation compared to the physical activation are lower treatment temperatures and shorter treatment times. In addition, activated carbon obtained by chemical activation exhibits a larger surface area and better developed mesoporosity than physical activation (Sricharoenchaikul, 2007, Jabit, 2007).

A number of reports abound on the preparation of activated carbon using various agricultural wastes
(Martinez et al., 2007, Wang et al., 2010), low-cost biomass materials such as shea nut shell (Itodo and Itodo, 2011), Parthenium biomass (Rajeshwari et al., 2010), rice husk (Wuana et al, 2007, Nasehir et al., 2010, Aloko and Adebayo, 2007 Goodhead and Dagde, 2011), coconut shell (Wei et al, 2006, Ash et al., 2006, Gimba and Muyiwa, 2008, Rahman et al., 2006), bituminous coal (Cuhadaroglu and Uygun, 2008), wood (Abdullah et al., 2001, Lysenko, 2007, Goodhead and Dagde, 2011 ), sugarcane bagasse (Qureshi et al., 2007), animal horns (Aluyor and Badmus, 2008), oil palm shells (Lua and Guo, 2001, Tan et al, 2008, Hameed et al, 2009), physic nut waste (Sricharoenchaikul et al., 2007) and periwinkle shells (Badmus et al., 2007) to name a few has been widely studied.

Activated carbon from periwinkle shell forms a cheap, effective, renewable and readily available source of activated carbon. Periwinkle shells are animal waste obtained from dumpsites or market places and are of no industrial importance besides use as land refill. They contain carbon which when carbonized and activated can serve as adsorbents which has various important applications in such areas as analytical chemistry, environmental studies, medicine, fuel storage, gas and chemical purification, distilled alcoholic beverage purification.

In this study, preparation of activated carbon from locally sourced aquatic waste, periwinkle shells using $\mathrm{ZnCl}_{2}$ as activating agent is advanced. Other applications of this salt for activation have been with agricultural materials such as corn cob, groundnut shell, coffee residue (Malik et al, 2006, Jambulingam et al., 2007, Oliveira et al, 2009). The use of acids and bases has variously been applied in previous 
research on periwinkle shell carbon (Badmus et al., 2007, Jabit, 2007). The implication of these research findings is that there is a dearth of reports on activated carbon prepared from periwinkle shells using $\mathrm{ZnCl}_{2}$ as activating agent. The focus of this paper therefore is to provide laboratory scale information on the effects of $\mathrm{ZnCl}_{2}$ on pyrolyzed periwinkle shell with a view to determining the impregnation ratio of $\mathrm{ZnCl}_{2}$ that would produce periwinkle shell with high sorption capacity.

\section{MATERIALS AND METHODS}

Materials: Carbonized periwinkle shell samples were obtained from previous study of Owabor et al., (2010).

Activation: $100 \mathrm{~g}$ of the carbonized sample was measured and placed in a plastic container which was then mixed with Zinc chloride pellets at an impregnation ratio (IR) ranging from 0.1 to 1.5 . The IR is calculated as shown below:

$\mathrm{IR}=\frac{\text { Wzncl } 2}{\text { Wrample(100g }}$

Where $W_{\mathrm{ZnCl} 2}$ is the weight of $\mathrm{ZnCl}_{2}$ and $W_{\text {sample }}$ is the weight of sample

Distilled water was then added to dissolve all the $\mathrm{ZnCl}_{2}$ pellets. The mixture was placed in a water bath and made to boil for 1 hour to allow impregnation after which it was cooled to room temperature. After cooling, the slurry was immersed in $1 \mathrm{M} \mathrm{HCl}$ solution for 24 hours to leach out the excess $\mathrm{ZnCl}_{2}$ on the activated carbon particles. It was then washed with hot distilled water until the $\mathrm{pH}$ of the supernatant was between 6.5 to 7 . The slurry was thereafter filtered. The filtered sample was subsequently dried in an oven at $100{ }^{0} \mathrm{C}$ until a constant mass was obtained. The dry activated carbon sample was stored in airtight plastic containers (Rajeshwari, 2010, Cuhadaroglu and Uygun, 2008, Abdullah et al., 2001).

Porosity: $10 \mathrm{~g}$ of AC sample was measured using an electron weighing balance into a graduated cylinder and was then tapped until there was no change in volume. The weighed sample in the measuring cylinder was then immersed into water in a beaker and brought to boil. After the pore has been displaced, the sample was superficially dried and weighed again. The weight divided by the density of water gives the pore volume porosity was therefore calculated from pore volume by dividing the pore volume of the particle with the total volume of the particle (Aloko and Adebayo, 2007).
Porosity $=\frac{W s-W d}{P_{v s}} \times \frac{1}{V p}$

$\mathrm{Wd}=$ Weight of dried sample; Ws = Weight of superficially dried wet sample; Pvs= density of water $\mathrm{Vp}=$ total volume of particles

Iodine Number: 2 drops of starch solution was added to $10 \mathrm{ml}$ of $0.1 \mathrm{~N}$ iodine solution in a conical flask. It was observed that the pale yellow of the iodine solution turned blue. The resulting solution was titrated with $0.05 \mathrm{~N}$ sodium thiosulphate until it became colourless. The burette reading corresponded to blank reading (B). $0.2 \mathrm{~g}$ of activated carbon was accurately weighed and introduced into a completely dry conical flask. $40 \mathrm{ml}$ of $0.1 \mathrm{~N}$ Iodine solution was added. The flask shaken for 4 minutes and the contents were filtered. The filtrate was collected in a dry flask after which $10 \mathrm{ml}$ of the filtrate was titrated against standard sodium thiosulphate solution using starch as indicator (Abdullah et al, 2001, Lori et al, 2007). The new burette readings corresponded to (A).

$$
\begin{aligned}
& \text { Lodine Value }=C \times C f\left({ }^{m g} / g\right) \\
& C f=\frac{\text { molwt of iodine }(127) \times N \times 20}{\text { wt of carbon } \times \text { blank }} \\
& C=B-A
\end{aligned}
$$

Where $\mathrm{Cf}=$ conversion factor; $\mathrm{N}=$ normality of iodine;

Carbon Yield: The weight of dry sample was measured before and after activation using the electric weighing machine using the procedure of Nasehir et al., (2010), Aloko and Adebayo, (2007). The \%carbon yield was calculated as:

$$
\% \text { carbon yield }=\frac{w a}{w b} \times 100 \%
$$

Where $w a=$ weight after activation; $w b=$ weight before activation

Ash content: $2.0 \mathrm{~g}$ of the activated carbon was heated at $500{ }^{\circ} \mathrm{C}$ for 4 hours, cooled in a dessicator and reweighed $(\mathrm{w})$ following the method described by Ekpete and Horsfall, (2011), Abdullah et al., (2001), Aloko and Adebayo, (2007).

$$
\text { Percentage ash content }=\frac{2.0-w}{2.0} \times 100 \%
$$

$p H: 2.0 \mathrm{~g}$ of the activated carbon sample was weighed and transferred into a beaker. $100 \mathrm{ml}$ of 
distilled water was measured, added to the beaker and the contents stirred for one hour. The samples were allowed to stabilize before the $\mathrm{pH}$ was measured using a pH meter (Ekpete and Horsfall, 2011, Wuana et al., 2007).

Bulk Density: $10 \mathrm{~g}$ of sample was weighed and transferred to a measuring cylinder. Shaking or tapping of the cylinder was avoided. The surface was leveled off with a spatula. The cylinder was then tapped until a constant volume was observed (Aloko et al., 2007) and the bulk volume determined as:

Bulk Density $=\frac{\text { mass of sample }(g)}{\text { volume of sample }\left(\mathrm{cm}^{3}\right)}$

Moisture Content: $2.0 \mathrm{~g}$ of the dried sample was weighed and placed in a washed, dried and weighed crucible. The crucibles were placed in an oven and dried at $105{ }^{\circ} \mathrm{C}$ to constant weight for $4 \mathrm{~h}$ (Ekpete and Horsfall, 2011, Aloko and Adebayo, 2007). The percentage moisture content (\%MC) was computed as follows:

$$
\% M C=\frac{\text { loss in wolght on drying }}{\text { initial sample weight }}
$$

Mean Particle Size: The weight average mean particle size was determined using the procedure adopted from Richardson et al., (2003), McCabe et al., (2005). $20 \mathrm{~g}$ of each sample was measured using the electric weighing machine and placed in test sieves, which were arranged according to various sizes of the screens. The amount retained on each screen was collected and weighed; this was done for each of the screens up to the final screen.

$\bar{D}_{w}=\sum_{i=1}^{n} x_{i} \bar{D}_{p i}$

$\bar{D}_{w}=$ mean particle size;

$\bar{D}_{\mathrm{n}}=$ the mesh size of each screen used in the sieving $x_{i}=$ the weight fraction of the particles retained on the screen

\section{RESULTS AND DISCUSSION}

Iodine Number: The amount of iodine adsorbed increased rapidly with increasing $\mathrm{ZnCl}_{2}$ impregnation and attained an optimum of $104.95 \mathrm{mg} / \mathrm{g}$ at an impregnation ratio of 1.0 after which a reduction was observed as shown in Fig 1 below. The increase in the iodine number was due to increase in pore formation and hence adsorptive capacity of the activated carbon as impregnation increased. The observed drop in iodine number drop may be due to abundant increase in the pore volume which eventually resulted to internal collapse of the pores. This result was found to be consistent with the report of Viswanathan et al., (2009).

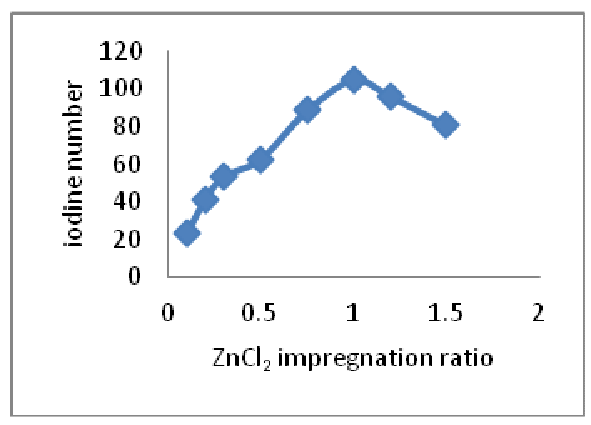

Fig 1: Variation of $\mathrm{ZnCl}_{2}$ impregnation ratio with iodine number

Ash Content: The influence of impregnation ratio on the $\%$ ash content of PSC shown in Figure 2 indicate that as the impregnation ratio increases, the ash content increased and reached an optimum point of $4.72 \%$ at impregnation ratio of 1.0 after which a decline was observed. The increase in ash content can be adduced to an increased formation of insoluble inorganic compounds with increase in IR. While the drop observed can be linked to a low char burn off at the respective IR.

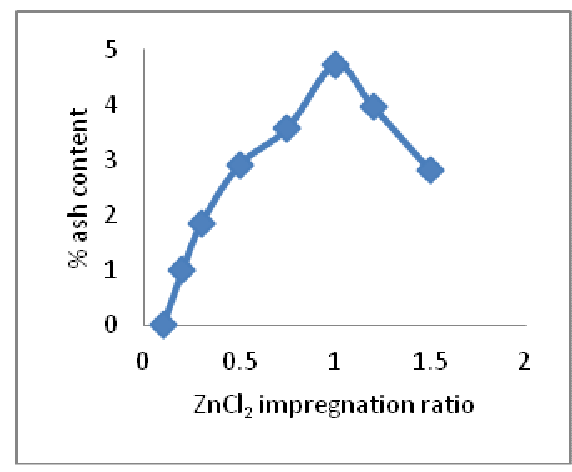

Fig 2: Effect of $\mathrm{ZnCl}_{2}$ impregnation ratio on ash content of PSC

$\boldsymbol{p H}$ : The $\mathrm{pH}$ decreased and attained a constant value as the impregnation ratio increased as shown in Figure 3. Again this can be attributed to the incidence of the metal salt hydrolyzing in the presence of natural alkalinity to form metal hydroxides thereby reducing the alkalinity of the carbonized periwinkle shells with impregnation. The constant $\mathrm{pH}$ observed between impregnation ratios of 1.0 and 1.5 might be due to the activating agent possessing similar hydrolyzing ability at these ratios. There is an increase in activated carbon adsorption property as the impregnation ratio increases because the 
percentage of adsorption decreases with increase in $\mathrm{pH}$.

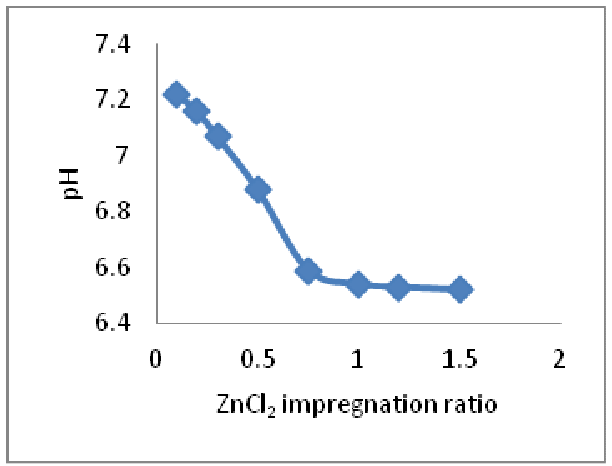

Fig 3: Effect of $\mathrm{ZnCl}_{2}$ impregnation ratio on $\mathrm{pH}$ of PSC

Bulk Density: The variation of the bulk density with the experimental $\mathrm{ZnCl}_{2}$ impregnation ratio used in this study showed that bulk density decreased with increasing impregnation ratio until a constant value was obtained as shown in Fig 4. The observed decrease in the bulk density may not be unrelated to the increase in pore volume resulting from increasing activation. The constant value observed between impregnation ratios 1.0 and 1.5 indicates that increasing impregnation no longer affected the pore size development due to a fully developed pore structure.

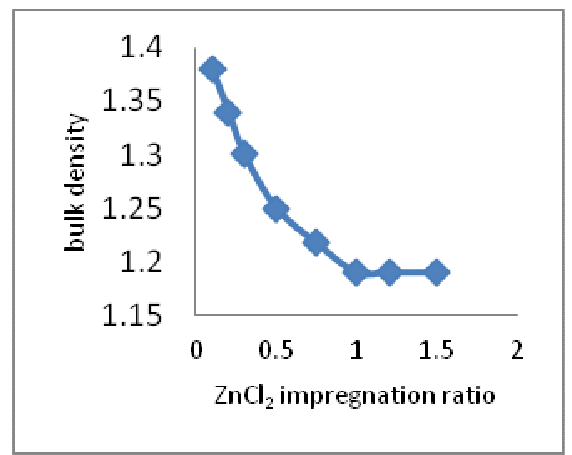

Fig 4: Effect of $\mathrm{ZnCl} 2$ impregnation ratio on bulk density of PSC

Percentage Carbon Yield: The result obtained showed that there was a weight loss when the carbonized samples were activated. The weight loss was due to devolatilization of the precursors as a result of intense dehydration and elimination reactions. This was primarily to increase the pore development and create new pores. The carbon yield increased as the concentration of $\mathrm{ZnCl}_{2}$ impregnating solution increased as presented in Figure 5 and approached an optimum point at $20 \%$ impregnation ratio of $\mathrm{ZnCl}_{2}$ with $95.25 \%$ yield. Experimental result revealed that a further increase in $\mathrm{ZnCl}_{2}$ loading led to a decrease in yield. This development may be attributed to the inhibition of tar formation and increased pyrolytic decomposition as the impregnation ratio increases. This observation is affirmed by the result of Rajeshwari et al., (2010).

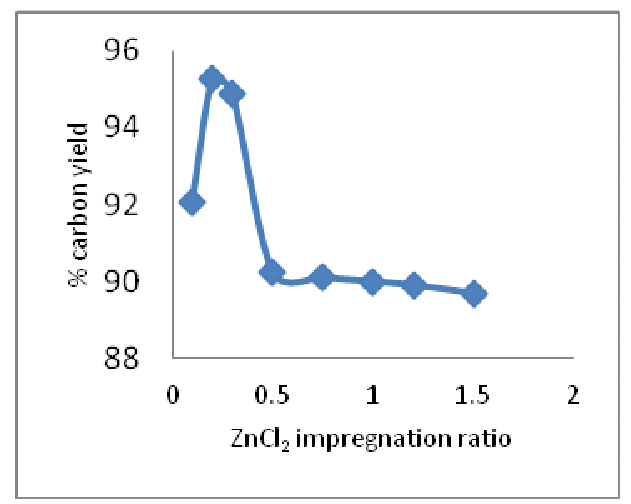

Fig 5: Effect of $\mathrm{ZnCl}_{2}$ impregnation ratio on carbon yield of PSC

Moisture Content: As observed in Figure 6, the moisture content decreased successively for $\mathrm{ZnCl}_{2}$ impregnation ratio ranging from 0.1 to 1.0 and thereafter became constant between impregnation ratios 1.0 and 1.5. This reason for the decrease could be deduced from the fact that dehydration rate of the activated carbon increased with impregnation ratio. The constant values obtained showed that a further increase in impregnation had little or no effect on the moisture content of the activated carbon produced.

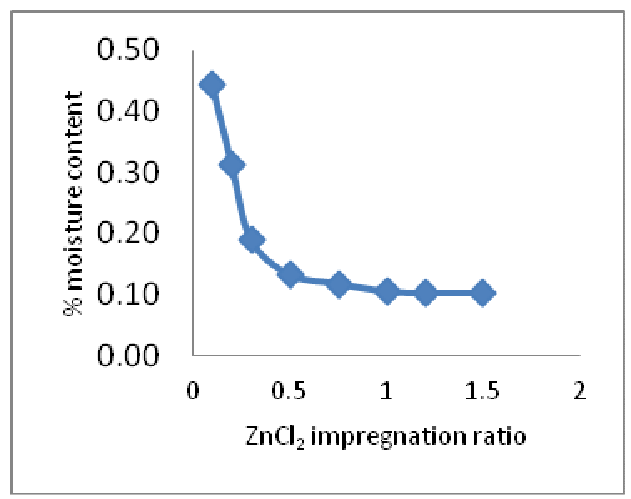

Fig 6: Effect of $\mathrm{ZnCl} 2$ impregnation ratio on moisture content of PSC

Porosity: The porosity of the activated PSC increased with increasing impregnation ratio and peaked at an optimum porosity of 0.003947 obtained at impregnation ratios 1.0 and 1.2. This occurrence was as a result of the elimination of large amount of internal carbon mass as explained by Sricharoenchaikul et al., (2007). The increased porosity suggests that pores were created by the reactant as a result of the spaces left by zinc chloride 
after washing (Marsh and Rodriguez-Reinoso, 2006). The constant value obtained between IR 0.2 and 0.3 and 1.0 and 1.2 may have arisen due to pseudo saturation and full saturation of the pores with increasing IR respectively. The decrease observed between impregnation ratios 1.2 and 1.5 maybe due to a breakdown in the physical structure of the precursor caused by excessive pore pathways thereby leading to shrinkage in particle size with increasing concentration of activating agent.

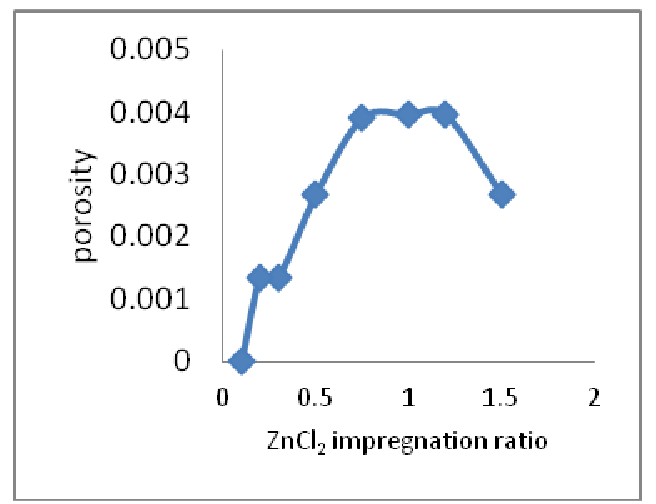

Fig 7: Effect of $\mathrm{ZnCl} 2$ impregnation ratio on porosity of PSC

Bulk Volume: The observed increase in the bulk volume may be due to increase in pore formation and hence bulk volume. The constant value observed between impregnation ratios 1.0 and 1.5 indicates that increasing impregnation no longer affected the pore size development due to a fully developed pore structure.

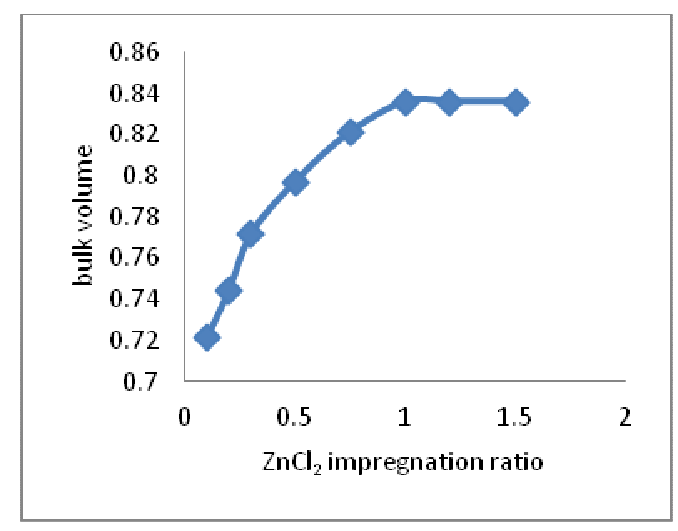

Fig 8: Effect of $\mathrm{ZnCl}_{2}$ impregnation ratio on bulk volume of PSC

Mean Particle Size: The finer the particle sizes of an activated carbon, the better the access to the surface area and the faster the rate of adsorption. Small particles have the fastest rate of attracting and attaching dissolved molecules to their surface (Marsh and Rodriguez-Reinoso, 2006). The observed decrease from $0.482138 \mathrm{~mm}$ to $0.420263 \mathrm{~mm}$ as the zinc chloride impregnation ratio increased from 0.1 to 1.0 may again be due to a breakdown in the physical structure of the precursor caused by excessive pore pathways leading to shrinkage in particle size with impregnation. However, a slight increase was observed between impregnation ratios 1.0 and 1.5. The observed increase may be attributed to an increase in the internal pore size and development of pore pathways leading to an increase in the overall particle size with increased impregnation. The result from this study affirms that the best particle size which would ensure increased sorption capacity of the activated PSC was obtained at impregnation ratio 1.0 .

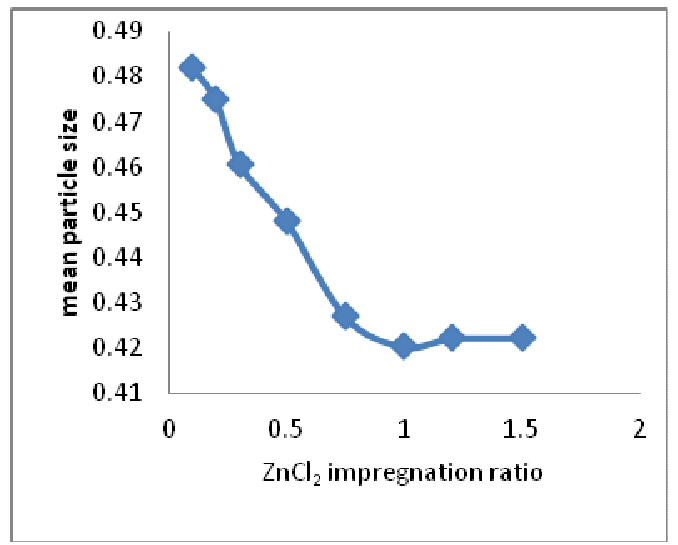

Fig 9: Effect of $\mathrm{ZnCl}_{2}$ impregnation ratio on mean particle size of PSC

Generally, the effectiveness of activated carbon as an adsorbent which is attributable to its unique properties including large surface area, high degree of surface reactivity, universal adsorption effect, and favourable pore size cannot be overemphasized. Porosity, iodine number, mean particle size and $\mathrm{pH}$ evaluated in this study that directly influence the suitability of an activated carbon sample for adsorption as these properties reflect the nature of internal pore development and adsorptive capacity (a measure of surface area) of the activated carbon.

Conclusion: Preparation of activated carbon from pyrolyzed periwinkle shell waste was performed in a laboratory scale facility. The data obtained indicated that activated carbon with favorable physiochemical properties may be produced from the methods advanced in this study. The effects of impregnation on the physiochemical properties of periwinkle under study affirm that the optimum impregnation of zinc chloride was obtained at IR 1.0. This impregnation ratio gave peak values for porosity and iodine number and minimal values for $\mathrm{pH}$ and mean particle 
size which are the properties used for assessing the suitability of activated carbon for purposes of adsorption.

\section{REFERENCES}

Abdul, H.A., Anuar, K., Zulkarnain, Z., Mohd, Z.H., Dzulkefly, K., Faujan, A. and Ong, S.W. (2001). Preparation and Characterization of Activated Carbon from Gelam Wood Bark (Melaleuca cajuputi), Malaysian Journal of Analytical Sciences, Vol. 7, No. 1, 65-68.

Aloko, D.F. and Adebayo, G.A. (2007). "Production and characterization of Activated carbon from Agricultural waste." Medwell Journals Vol. 2, No.2, 440-444.

Aluyor, E.O. and Badmus, M.A.O. (2008). “COD removal from industrial waste water using activated carbon prepared from animal horns." African Journal of Biotectnology, Vol.7 (21), 3887-3891.

Ash, B., Satapathy, D., Mukherjee, P.S., Nanda, B., Gumaste, J.L. and Mishra, B.K. (2006). "Characterisation and application of activated carbon prepared from waste coir pith.” Journal of Scientific and Industrial Research, Vol.65, 10081012.

Badmus, M.A.O., Audu T.O.K. and Anyata B.U. (2007). "Removal of Copper from Industrial Wastewaters by Activated Carbon Prepared from Periwinkle Shells (Typanotonus fuscatus)." Turkish J. Eng. Env. Sci. 24: 251-263.

Boudrahem, F., Soualah, A. and Aissani-Benissad, F. (2011). " $\mathrm{Pb}(11)$ and $\mathrm{Cd}(11)$ removal from aqueous solution using activated carbon with phosphoric acid and zinc chloride." J. Chem. Eng. Data, 56(5), 1946-1955.

Cuhadaroglu, D. and Uygun, O.A. (2008). "Production and characterization of activated carbon from a bituminous coal by chemical activation." African Journal of Biotechnology Vol. 7, No. 20, 3703-3710

Ekpete, O.A. and Horsfall, M. JNR, (2011). "Preparation and Characterization of Activated Carbon derived from Fluted Pumpkin Stem Waste (Telfairia occidentalis Hook F)." Research Journal of Chemical Sciences, Vol. 1, No. 3, 1-5.
Gimba, C.E. and Muyiwa, T. (2008). “ Optimum conditions for carbonization of coconut shell". Scientia Africana. Vol.7 (No.2), 12-21.

Goodhead, T. O. and Dagde, K. K. (2011). "Adsorption of Acetic Acid, Cadmium ions, Lead ions and Iodine Using Activated Carbon from Waste Wood and Rice Husks." J. Appl. Sci. Environ. Manage.Vol. 15 (2), 407-410.

Hameed, B.H., Tan, I.A.W. and Ahmad, A.L. (2009). "Preparation of oil palm empty fruit bunchactivated carbon for removal of $2,4,6-$ trichlorophenol: optimization using response surface methodology." Journal of Hazardous Materials, Vol.164, Issues 2-3, 1316-1324.

Itodo, A.U. and Itodo, H.U. (2011). “Application of isotherm studies on the evaluation of sorption energies for dyestuff removal onto derived thermo-cracked shea nut shells." Research Journal of Pharmaceutical, Biological and Chemical Sciences Vol. 2, No.1, 683

Jabit, N.B. (2007). "The production and characterization of activated carbon using local agricultural waste through chemical activation process." A master thesis from Faculty of Engineering, Zonguldak Karaelmas University, Zonguldak, Turkey

Jambulingam, M., Karthikeyan, S., Sivakumar, P., Kiruthika, J. and Maiyalagan, T. (2007). "Characteristic studies of some activated carbons from agricultural wastes." Journal of Scientific and Industrial Research, Vol.66, 495-500.

Lori, J. A., Lawal, A. O. and Ekaem, E. J. (2007). "Characterisation and optimization of deferration of kankara clay." Journal of Engineering and Applied Sciences, Vol. 2, No. 5, 60-74.

Lua, A.C. and Guo, J. (2001). Microporous oil-palmshell activated carbon prepared by physical activation for gas adsorption." Langmuir, 17(22), 7112-7117.

Lysenko, A.A. (2007). "Prospect for development of research and production of carbon fibre sorbents." Fibre Chemistry, Vol.39, No.2, 93102.

Malik, R., Ramteke, D.S. and Wate, S.R. (2006). "Physico-chemical and surface characterization of adsorbent prepared from groundnut shell by $\mathrm{ZnCl}_{2}$ activation and its ability to adsorb colour." 
Indian Journal of Chemical Technology, Vol.13, 319-328.

Marsh, H. and Rodriguez-Reinonso, F. (2006). Activated carbon Elsevier Science \& Technology Books, Amsterdam, $1^{\text {st }}$ edition 89-100, 321-375.

Martinez, M.L., Moiraghi, L., Agnese, M. and Guzman, C. (2007). "Making and Some Properties of Activated Carbon Produced from Agricultural Industrial Residues From Argentina." The journal of the Argentine Chemical Society Vol.91-No4/6, 103-108.

McCabe, L.W., Smith, C.J. and Harriot, P. (2005) Unit Operations of Chemical Engineering, $6^{\text {th }}$ Edition, 927-935.

Nasehir, K.E.M., Yahaya, M.F., Ismail, A. and Mohd, A.A. (2010). "Effect of preparation conditions of activated carbon prepared from rice husk by $\mathrm{ZnCl} 2$ activation for removal of $\mathrm{Cu}$ (II) from aqueous solution." International Journal of Engineering \& Technology IJET-IJENS Vol: 10 No: 06, 27-31

Oliveira, L.C.A., Pereira, E., Guimaraes, I.R., Vallone, A., Pereira, M., Mesquita, J.P. and Sapag, K. (2009). Preparation of activated carbons from coffee husks utilizing $\mathrm{FeCl}_{3}$ and $\mathrm{ZnCl}_{2}$ as activating agents." Journal of Hazardous Materials, Vol.165, Issues 1-3, 87-94.

Owabor, C.N., Ayodele, B.V and Etemah, J. T. (2010). "Temperature effects on the carbonization of periwinkle shell". Journal of Engineering for Development. Vol. 9, April, 130-141.

Qureshi, K., Bhatti, I., Kazi, R and Ansari, A.K. (2007). "Physical and chemical analysis of activated carbon prepared from sugarcane baggasse and use for sugar decolorization". World Academy of Science, Engineering and Technology. 34, 194-198.

Rahman, M.A., Asadullah, M., Haque, M.M., Motin, M.A., Sultan, M.B. and Azad, A.K. (2006). "Preparation and characterization of activated charcoal as adsorbent". J. Surface Sci. Technol.

Vol.22, No.3-4, 133-140.

Rajeshwari, S., Venckatesh, R. and Sangeetha, G. (2010). "Preparation and Characterization of Activated Carbons from Parthenium Biomass by Physical and Chemical Activation Techniques."
E-Journal of Chemistry, Vol 7, No. 4, 13141319.

Richardson, J.F., Harker, J.H. and Backhurst, J.R. (2003). Chemical Engineering, Butterworth Heinemnn, An Imprint of Elsevier, India, Vol. 2, $5^{\text {th }}$ edition. Sharma, J. and Janveja, B. (2008). “A study on removal of congo red dye from the effluents of textile industry using rice husk carbon activated by steam." Rasayan J. Chem. Vol.1, No.4, 936-942.

Sricharoenchaikul, V., Chiravoot, P. and Duangduen, A. (2007). Preparation and Characterization of Activated Carbon from the Pyrolysis of Physic Nut (Jatropha curcas L.) Waste. Department of Environmental Engineering, Faculty of Engineering, Chulalongkorn University, Bangkok 10330 Thailand, 1-7.

Tan, I.A.W., Ahmad, A.L. and Hameed, B.H. (2008). "Adsorption of basic dye using activated carbon prepared from oil palm shell: batch and fixed bed studies." Desalination, 225, 13-28.

Viswanathan, B., Indra, P.N. and Varadarajan, T.K. (2009). "Methods of Activation and Specific Applications of Carbon Materials National centre for catalysis research." Indian Institute of Technology Madras Vol.2, No.4, 021- 036.

Wang, J., Wu, F., Meng, W., Ning, Q., Yao, L., ShuiQin, F. and Xing J. (2010). "Preparation of activated carbon from a renewable agricultural residue of pruning mulberry shoot." African Journal of Biotechnology Vol. 9 (19), 27622767.

Wei, S., Li, Z. and Yaping, Z. (2006). "Preparation of microporous activated carbon from raw coconut shell by two-step procedure." Chinese J. of Chemical Engineering, Vol.14 (2), 266-269.

Wuana, R.A., Okieimen, F.E. and Amua, Q.M. (2007). Aqueous Phase Adsorption of Organics onto Rice Hull Carbon Modified with Oxalic Acid." Continental J. Applied Science 1:38-41. 